\title{
A recomposição da história política e das ideias a partir da história dos conceitos de Reinhart Koselleck ${ }^{\mathrm{I}}$
}

Tenner Inauhiny de Abreu ${ }^{\text {II }}$

Resumo: O presente ensaio discute, de forma sumária, algumas questões em torno das possibilidades teórico-metodológicas e uma vinculação da história política e das ideias, mesmo que de maneira renovada, à história dos conceitos de Reinhart Koselleck. Tal escolha faz parte das discursões em torno da História Política, mais especificamente uma abordagem social do político. Justifica-se a escolha do tema por compreendermos a relevância, para a teoria do pensamento político e social das contribuições do projeto intelectual de Koselleck conhecido com história conceitual, para o campo atual da história do político.

Palavras-chave: História política; história das ideias; história dos conceitos

\section{The reconstitution of political history and ideas from the history of Reinhart Koselleck's concepts}

\begin{abstract}
This essay briefly discusses some questions about theoretical-methodological possibilities and a linkage of political history and ideas, albeit in a renewed way, to the history of Reinhart Koselleck's concepts. Such a choice is part of the discourses around Political History, more specifically a social approach to politics. The choice of theme is justified because we understand the relevance to the theory of political and social thought of the contributions of Koselleck's intellectual project known with conceptual history to the current field of political history.
\end{abstract}

Keywords: Political history; history of ideas; history of concepts

Artigo recebido em 17/03/2018 e aprovado em 29/05/2018.

Cadernos do Tempo Presente, São Cristóvão-SE, v. 09, n. 01, p. 55-63, jan./jun. 2018| http://www.seer.ufs.br/index.php/tempo 


\section{A RECOMPOSIÇÃO DA HISTÓRIA POLÍTICA E DAS IDEIAS A PARTIR DA HISTÓRIA DOS CONCEITOS DE REINHART KOSELLECK}

TENNER INAUHINY DE ABREU

\section{Da história político-intelectual à história filosófica do político.}

A partir da segunda metade do século XX, a então renovada história política e das ideias passa por uma recomposição de suas bases epistemológicas, ocorrida notadamente na Alemanha com a história dos conceitos de Reinhart Koselleck. Durante boa parte do século, o espaço concedido à história político-intelectual fícou marginalizado, por conta dos ataques efetuados pela história social, pela história das mentalidades e pelo marxismo.

O termo história intelectual possui um sentido estrito no mundo anglo-saxão. Importante frisar a diferença de uma história do político, que segundo o autor é frequentemente confundida com uma história das ideias (numa visão clássica) que se restringe a uma história dos grandes autores. Esta abordagem antiga da história das ideias, enquanto campo foi abandonado pelos acadêmicos franceses, o que na visão de Rosanvallon gerou a necessidade de uma reconstrução histórica mais tradicional, antes de se buscar uma perspectiva de uma história conceitual do político. A história conceitual do político não rejeita totalmente os métodos tradicionais da história das ideias, dos eventos, das instituições ou mesmo das mentalidades, e sim reavalia temas de pesquisas próprios a ela, a partir de novos pontos de vista. ${ }^{\text {III }}$

Skinner em Significação e compreensão na história das ideias afirma que a missão do historiador das ideias é estudar e interpretar um cânone de textos clássicos, sendo que a importância de se escrever este tipo de história reside no fato destes textos conterem uma sabedoria intemporal, expressa em ideias universais. Ressalta que a melhor maneira de abordar esses textos clássicos é lermos tais textos como se tivessem sido escritos no tempo contemporâneo. É para o autor, fundamental uma concentração nos argumentos apresentados, além da necessidade de se enveredar por uma análise das condições sociais ou dos contextos intelectuais em que esses textos foram escritos. ${ }^{\text {IV }}$

O dilema da história das ideias, para Skinner é que ela teria pretensão de se concentrar naquilo que os textos clássicos dizem, entretanto conforme assinala, não é possível estudar apenas o que um escritor disse, sob pena de que se ponha neste quadro as expectativas e preconceitos do próprio observador. Na esteira do que afirma o autor, através da nossa experiência passada somos inclinados a interpretar determinados aspectos de uma certa maneira, reagindo a uma quadro de referências já previamente definido.

O debate contemporâneo acerca do fazer história do pensamento político e social, coloca-nos frente ao que classifica como as duas vertentes mais produtivas no campo da disciplina histórica, ou seja, o contextualísmo linguístico de Quentin Skinner e a história dos conceitos de Koselleck. Conforme ressalta, o debate do que seriam formas válidas da história do pensamento para a teoria política e social, passa pelas considerações críticas feitas por Skinner, contra várias tradições da história das ideias políticas.

Tais tradições incorriam em anacronismos, o que pode ser notado na fala supracitada de Skinner: a imputação a autores e obras intenções e significados que não tinham, sendo resultado destas histórias criticadas a produção de mitologias históricas.

Cadernos do Tempo Presente, São Cristóvão-SE, v. 09, n. 01, p. 55-63, jan./jun. 2018| http://www.seer.ufs.br/index.php/tempo 


\section{A RECOMPOSIÇÃo DA HISTÓRIA POLÍTICA E DAS IDEIAS A PARTIR DA HISTÓRIA DOS CONCEITOS DE REINHART KOSELLECK}

\section{TENNER INAUHINY DE ABREU}

Conforme ressalta Marcelo Jasmin, Skinner afirmava que as interpretações sobre as ideias do passado tomavam conceitos e argumentos desconsiderando seus significados originais. Skinner alerta que o anacronismo, para a história da filosofia, implicaria na ampliação de obstáculos à teoria política, na medida em que os trabalhos elaborados seriam atos de fala, inseridos em contextos políticos e linguagens próprias.

Uma das definições já consideradas clássica sobre a história política, que corrobora com a visão da escola dos Annales é a de Jacques Julliard presente na obra História: novas abordagens. $\mathrm{O}$ autor em $A$ política afirma que a história política tinha má reputação entre os historiadores franceses, pois era vítima de sua solidariedade com formas mais tradicionais da historiografia do começo do século XX. A referida história política seria caracterizada como uma história factual marcada por ser elitista, idealista e psicológica. $^{\text {VI }}$

Apesar desta crítica ter sido escrita em referência ao espaço acadêmico francês dos anos 1970, cristalizou-se uma visão de desinteresse pelo campo político, ou utilizando as palavras de Julliard, um desprezo pelo fenômeno político, mesmo com o autor fazendo alusão a uma "volta do político".

De acordo com Rosanvallon, o "retorno do político" se deu acompanhado do desencantamento com as ciências sociais, conforme destaca, visível na década de 1980 . Nesse contexto de crítica e pessimismo com a sociologia e a antropologia emergiu a história filosófica do político. Conforme já assinalado, o mencionado "retorno ao político", no final da década de 1960, surge neste momento da história a redescoberta do tema da democracia e de sua problemática natureza. Na década de 1970 há, para Rosanvallon, uma análise mais profunda do problema da democracia devido a crítica ao totalitarismo e desde o fim dos anos 1980, observa-se um contexto caracterizado pela ascenção do nacionalismo e crise do Estado de Bem-Estar. ${ }^{\text {VII }}$

No campo da teoria política e das ideias, Finley, em oposição ao que afirma Julliard sobre o caráter idealista da história política, (no caso de Finley das ideias) ressalta que a história das ideias nunca é apenas das ideias, mais também a história das instituições, da própria sociedade. Finley faz tal afirmação ao discutir o que classifica como o problema da democracia na sociedade moderna. Para reafirmar a vinculação entre a história das ideias e a história política, o autor destaca que a democracia (tema de sua obra) é um problema maior das duas disciplinas. ${ }^{\text {VIII }}$

É necessário retomarmos a argumentação de Rosanvallon em torno da história filosófica do político, que ao contrário da história das ideias clássica, não se limita a uma análise e comentário de grandes textos. A história filosófica do político, conceito intercambiável, para o autor, em relação a história conceitual do político, preocupa-se em incorporar elementos que produzem, complexamente a cultura política. Por ser uma história multifacetada, tal abordagem se relaciona tanto com uma história dos eventos e das instituições, em permanente construção, quanto pela história das mentalidades.

A história filosófica do político consiste, para Rosanvallon, em reunir portanto, todos os materiais empregados por historiadores das ideias, das mentalidades, das instituições e dos eventos. Nesse sentido tal abordagem representaria uma história

Cadernos do Tempo Presente, São Cristóvão-SE, v. 09, n. 01, p. 55-63, jan./jun. 2018| http://www.seer.ufs.br/index.php/tempo 


\section{A RECOMPOSIÇÃO DA HISTÓRIA POLÍTICA E DAS IDEIAS A PARTIR DA HISTÓRIA DOS CONCEITOS DE REINHART KOSELLECK}

\section{TENNER INAUHINY DE ABREU}

política total, a fim de construir o sentido do político, de forma complexa. Tal aspecto se dá, por conta da constante renovação da história, em decorrência dos debates contemporâneos de suas fronteiras em que a nova história filosófica do político deve ser compreendida.

Lynch em oposição a crítica de Julliard, cita François Furet para reforçar a noção de que a história política é ao mesmo tempo a história das ideias e também de sua recepção social. Furet via no ofício do historiador a tarefa da história intelectual de devolver a dimensão política à historiografia que havia sido privada pelos marxistas e pela escola dos Annales.

Ainda se afastando da definição de Julliard, na esteira da "volta do político", Pierre Rosanvalon na obra Le sacre du citoyen. Histoire du suffrag universal em France, em consonância as assertivas de Lynch e Finley, tanto sobre a relação da história intelectual e da história política, demonstrando que estas não são meramente idealistas ou psicologizantes, ao abordar a temática do sufrágio universal, descendo a prática da análise das fontes, afirma que fazer a história do sufrágio universal no século XIX, consiste em explorar um núcleo denso, a história de uma instituição. ${ }^{\text {IX }}$

Para Rosanvallon ${ }^{\mathrm{X}} \mathrm{o}$ político seria responsável pela conformação do social, fato observável nas instituições, enquanto a política seria um subsistema tanto quando o econômico, social ou o religioso, o que o aproximaria de uma aplicação metodológica às fontes, de uma problemática vinculada a história dos conceitos de Koselleck.

Para Rosanvallon ${ }^{\mathrm{XI}}$ a história filosófica do político se equivoca ao distinguir entre o discursivo e o não-discursivo. Tal abordagem, para o autor, deve considerar que as representações sociais não podem ser igualadas às ideologias, nem reduzidas à condição de preconceitos.

A história filosófica do político postula a existência de representações positivas que organizam o campo intelectual em dado momento histórico, sendo constituições reais e poderosas de infra-estruturas sociais, fato que se oporia a uma visão idealista. As ideias, que tal abordagem levam em conta, constituem uma parte da realidade. Os fatos da história, ainda de acordo com Rosanvallon ${ }^{\mathrm{XII}}$, apenas revelam seu significado quando colocados em um contexto ou inseridos numa história conceitual, sendo que esta não se restringe apenas à análise de grandes autores, conforme já mencionado anteriormente.

Rosanvallon $^{\mathrm{XIII}}$ reconhece a relevância e a importância da chamada história contextual das ideias, definidas por Quentin Skinner ${ }^{\mathrm{XIV}}$, que tem buscado ir além de uma leitura filosófica de grandes autores, baseada numa perspectiva limitada ou texto, que tende a reduzir os escritos políticos à condição de produtos ideológicos. Para o autor, Skinner buscou ler os textos como atos linguísticos em universos de significados reconhecíveis. Essa é para Rosanvallon, uma perspectiva que tem conduzido a uma ampla renovação da história das ideias, pois possibilita um diálogo entre historiadores e filósofos.

Cadernos do Tempo Presente, São Cristóvão-SE, v. 09, n. 01, p. 55-63, jan./jun. 2018| http://www.seer.ufs.br/index.php/tempo 


\section{A RECOMPOSIÇÃO DA HISTÓRIA POLÍTICA E DAS IDEIAS A PARTIR DA HISTÓRIA DOS CONCEITOS DE REINHART KOSELLECK}

\section{TENNER INAUHINY DE ABREU}

\section{Teoria política e social e história conceitual}

Marcelo Jasmin ${ }^{\mathrm{XV}}$ destaca a história conceitual alemã, desenvolvida por Koselleck, como relevante nos debates contemporâneos acerca das perspectivas teóricometodológicas do fazer história do pensamento político e social.

Contextualizando a gênese da história dos conceitos, Jasmin ${ }^{\mathrm{XVI}}$ afirma que esta, foi inicialmente desenvolvida pelo historiador Otto Brunner, na sua crítica à historiografia jurídica e liberal alemã, notadamente a maneira particular como se transpunham para a realidade medieval conceitos posteriores. A história dos conceitos se proliferou, para o autor, como derivada de uma história reflexiva da filosofia e do pensamento político e social, se desenvolvendo contemporaneamente sobre a influência da hermenêutica e da filosofia.

Conforme assinala Jasmin, ${ }^{\text {XVII }}$ o projeto intelectual de Koselleck, que se convencionou classificar na atualidade como história dos conceitos, surgiu do impulso crítico a transferência descuidada para o passado de expressões modernas e da prática das histórias das ideias de tratá-las como constantes. O contexto das décadas de 1950 e 1960 acompanhou a perspectiva das insuficiências teóricas da história, principalmente as vertentes da história do espírito, de influência hegeliana e da história das ideias influenciada por Dilthey.

Para Koselleck XVIII a história dos conceitos teria como problemática se questionar a partir de quando determinados conceitos seriam resultados de um processo de teorização. Essa problemática só seria possível de ser desenvolvida empiricamente, a partir de um trabalho com as fontes. Metodologicamente todo conceito articula-se a um certo contexto sobre o qual pode atuar. Um conceito se relaciona aquilo que se quer compreender, ou seja, o conceito e seu conteúdo, mesmo sendo um fato linguístico, podem atuar sobre a realidade de forma concreta.

Koselleck $^{\mathrm{XIX}}$ alerta que a língua é fundamental na compreensão e no uso de certos conceitos, pois constrói-se através do conjunto da língua, uma cadeia que articula um conceito a outro, que possibilita a observação da articulação entre conceitos. Para o autor, a história dos conceitos pode ser pensada a partir de um procedimento metodológico de seleção daquilo que se relaciona a um conceito e o que não diz respeito ao mesmo.

Em ralação ao método da história dos conceitos, Koselleck ${ }^{\mathrm{XX}}$ ressalta os aspectos práticos que estão vinculados ao trabalho com as fontes. Para o autor, a separação analítica entre as afirmações linguísticas estão presentes em todas as fontes textuais e são distintas da história concreta. Tais aspectos deveriam ser tratados enquanto elementos relacionados a teoria. Só tendo esta perspectiva bem clara, o historiador pode perguntar as fontes textuais o que elas indicam em relação a história concreta.

Como resolver tais problemas práticos em relação à análise de fontes? O próprio Koselleck ${ }^{\mathrm{XI}}$ nos fornece indícios de como proceder enquanto projeto de pesquisa vinculado a uma história dos conceitos. Em relação a questões semânticas e sobre a

Cadernos do Tempo Presente, São Cristóvão-SE, v. 09, n. 01, p. 55-63, jan./jun. 2018| http://www.seer.ufs.br/index.php/tempo 


\section{A RECOMPOSIÇÃO DA HISTÓRIA POLÍTICA E DAS IDEIAS A PARTIR DA HISTÓRIA DOS CONCEITOS DE REINHART KOSELLECK}

\section{TENNER INAUHINY DE ABREU}

relação entre repetição e unicidade/singularidade de termos o autor é enfático: "Tomemos os dicionários. Pode-se traduzir o que cada palavra significa" (p.144). Determinados conceitos são multifacetados e plurivalentes, no que o autor destaca que empiricamente pode-se observar as limitações e especificações restritas a cada conceito através da análise dos dicionários, de maneira comparativa para constatar quando numa língua determinado conceito altera-se em ralação a outra língua.

Koselleck ${ }^{\mathrm{XXII}}$ ressalta: "Através desta fonte pode-se constatar, por exemplo quando na língua alemã o conceito moderno de Estado supera aquele de Estado como ordem, tomando-se mesmo seu oposto. A palavra é a mesma, mas ganhou outro valor." Indica ainda a relevância não apenas de se trabalhar com dicionários, mais também as enciclopédias, pois estas têm por finalidade a descrição normativa dos conteúdos.

Tomemos como exemplo do exercício empírico da história conceitual, enquanto projeto intelectual de Koselleck ${ }^{\mathrm{XXIII}}$, sua tese de doutorado Crítica e crise. O referido autor utiliza nesta obra além de fontes primárias: Barclay, D’Aubigné, Hobbes, Vattel, Lock, Lessing, Schiller, Voltaire, Diderot, Turget, panfletos anônimos e outros textos para discutir a gênese da utopia no contexto do século XVIII, ou a elaboração do significado político do Iluminismo sobre a estrutura do Estado absolutista.

Koselleck destaca que sua abordagem está vinculada a uma história das ideias e análises sociológicas das condições, sendo em suas palavras, uma abordagem heurística. Em relação as suas fontes o autor alerta, que só recorreu para desenvolver sua pesquisa, a fontes do período anterior a 1789, na medida em que afirma que seu tema é a unidade dos eventos do Iluminismo no Estado absolutista:

Cada ato de pensamento e cada ação deveriam nos remeter a esse
acontecimento. Do ponto de vista desta investigação, todos os autores são
representativos (...) Daremos a palavra, indistintamente, a grandes
pensadores e a panfletos anônimos, pois, na unidade dos eventos do
iluminismo, anonimato e importancia politica geralmente coincidem. XxIV

Conforme já destacamos, o método utilizado por Koselleck em Crítica e crise está inserido no campo da história das ideias:

Estudam-se os movimentos das ideias, mas somente na medida em que eles
permitam explicar seu acento político; examinam-se as situações em que as
ideias foram concebidas e sobre as quais repercutiram em seguida, mas
somente na medida em que elas permitam destacar o sentindo de que as
ideias se investiram. Não se trata portanto, de descrever o desenrolar político
de um lado, e as transformações das ideias, enquanto meras ideias, do outro.
As condições gerais que originaram o Iluminismo às quais ele reagiu não
mudaram no decorrer do século XVIII. Mudaram as circunstâncias - de uma
maneira, é claro, que acentuou ainda mais as dificuldades básicas do sistema
absolutista.

Efetivamente podemos extrair das palavras de Koselleck que sua investigação, ao demostrar o contexto geral da crise do Estado absolutista, concentra-se do lado político do processo, notadamente e usando suas palavras: “(...) o fermento da crítica muda o curso dos eventos políticos"XXVI

Cadernos do Tempo Presente, São Cristóvão-SE, v. 09, n. 01, p. 55-63, jan./jun. 2018| http://www.seer.ufs.br/index.php/tempo 


\title{
A RECOMPOSIÇÃO DA HISTÓRIA POLÍTICA E DAS IDEIAS A PARTIR DA HISTÓRIA DOS CONCEITOS DE REINHART KOSELLECK
}

\section{TENNER INAUHINY DE ABREU}

Outro autor a utilizar os procedimentos metodológicos, da história conceitual,

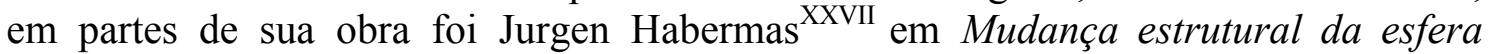
pública, inclusive e mais especificamente em seu capítulo IV Esfera pública burguesa: ideia e ideologia. Citando Koselleck ao longo do texto a influência fica clara ao observar-se o desenvolvimento da análise do autor em torno do que ele denomina "préhistória do topos". Ao descrever o que classifica como auto-entendimento da função da esfera pública burguesa, em suas palavras, que se cristalizou no topos da "opinião pública", Habermas XXVIII detecta que tal significado, ou seja, uma possível introdução da ideia de esfera pública burguesa teria uma articulação entre a sua pré-história, até a articulação do seu significado no século XVIII. Analisa à luz do contexto inglês, francês e alemão as mudanças dos termos public opinion; opinion publique e offentliche meinung.

Habermas assinala:

\begin{abstract}
'opinion' assume em inglês e em francês o sentindo nada complicado do termo latino opinio (...) opinion no sentindo de uma concepção incerta, que primeiro ainda teria de passar pelo teste da verdade, liga-se a opinion no sentido de um modo de ver da multidão (...) Compostos como: commom opinion, general opinion e vulgar opinion, ainda faltam completamente em Shakespeare; de jeito nenhum ele fala de public opinion, também não de public espirit. Assim também em francês, usos e costumes sobretudo concepções correntes e convenções muito difundidas, são chamadas sem qualquer rodeio de 'les opinions' ${ }^{\text {XXIX }}$
\end{abstract}

Observa-se nesse trecho supracitado o esforço do autor em comparar textos em línguas distintas, tal qual as determinações metodológicas de Koselleck, demonstrar o contexto de mudança e desenvolvimento, o que poderíamos chamar conceito, para Habermas, categoria de opinião pública para o ideal-tipo de esfera pública burguesa.

\section{Conclusão}

Ao longo da segunda metade do século XX a história política teve decretado seu "retorno". Durante muito tempo, diversas correntes criticavam o que denominavam de insuficiências do campo da história política e das ideias tradicional. Historiadores como Rosanvallon, ao se debruçarem sobre o problema da democracia (central em sua avaliação para o mundo contemporâneo) e Jurgen Habermas ao analisar a gênese da esfera pública dita burguesa recorrem, como podemos observar às discursões teóricometodológicas da história conceitual de influência de Koselleck.

A história conceitual enquanto projeto intelectual de Koselleck é considerada como uma possibilidade de renovação para a história politica e das ideias, fato que a coloca na centralidade dos debates em torno da disciplina histórica e da Teoria do pensamento político e social.

Cadernos do Tempo Presente, São Cristóvão-SE, v. 09, n. 01, p. 55-63, jan./jun. 2018| http://www.seer.ufs.br/index.php/tempo 


\title{
A RECOMPOSIÇÃO DA HISTÓRIA POLÍTICA E DAS IDEIAS A PARTIR DA HISTÓRIA DOS CONCEITOS DE REINHART KOSELLECK
}

\author{
TENNER INAUHINY DE ABREU
}

\section{Notas}

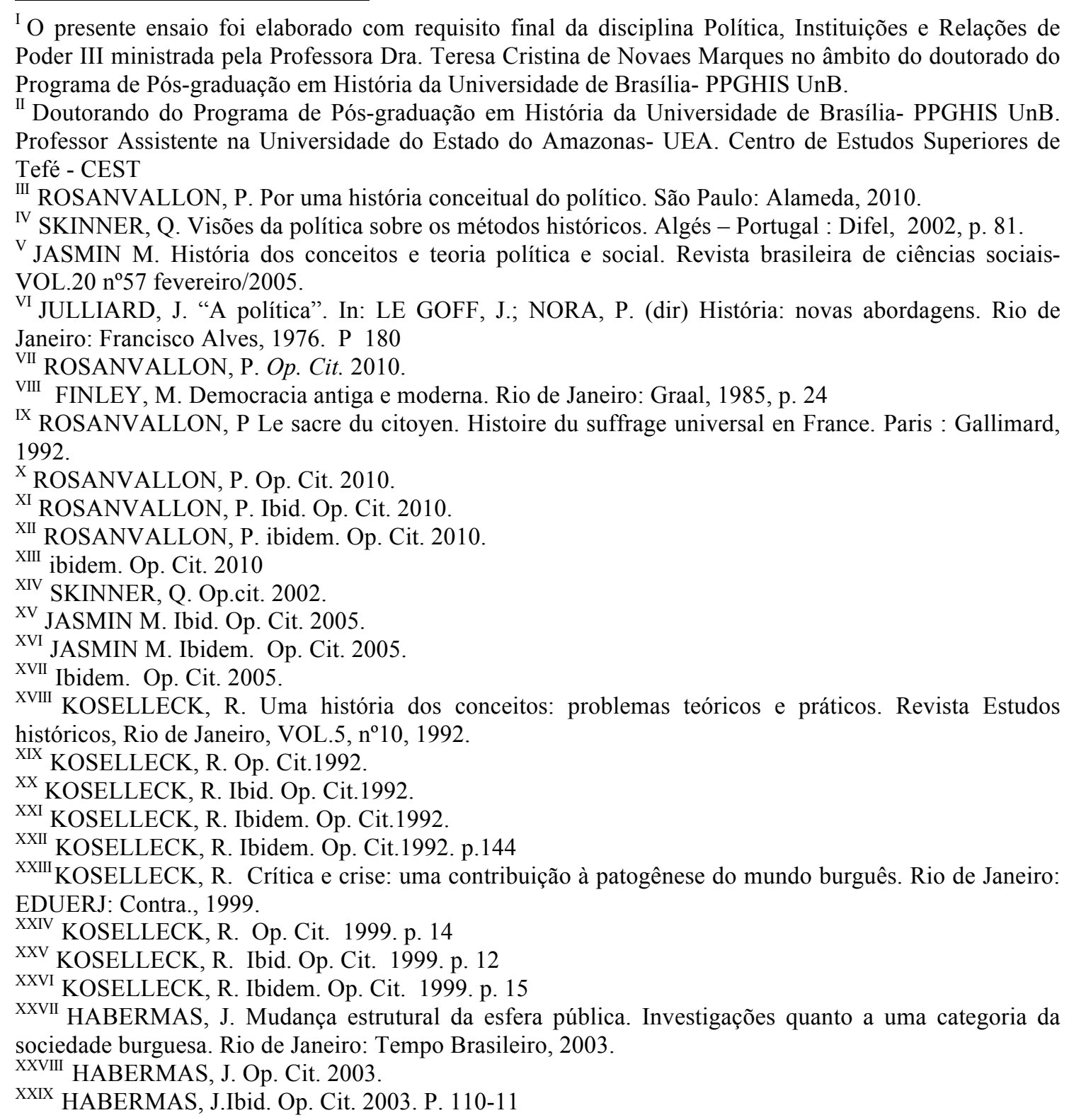

\section{Referências bibliográficas}

FINLEY, M. Democracia antiga e moderna. Rio de Janeiro: Graal, 1985. HABERMAS, J. Mudança estrutural da esfera pública. Investigações quanto a uma categoria da sociedade burguesa. Rio de Janeiro: Tempo Brasileiro, 2003. JASMIN M. História dos conceitos e teoria política e social. Revista brasileira de ciências sociais- VOL.20 nº57 fevereiro/2005. 
JULLIARD, J. “A política”. In: LE GOFF, J.; NORA, P. (dir) História: novas abordagens. Rio de Janeiro: Francisco Alves, 1976.

KOSELLECK, R. Uma história dos conceitos: problemas teóricos e práticos.

Revista Estudos históricos, Rio de Janeiro, VOL.5, nº10, 1992.

.Crítica e crise: uma contribuição à patogênese do mundo burguês.

Rio de Janeiro: EDUERJ: Contra., 1999.

LYNCH, C. A democracia como problema Pierre Rosanvallon e a Escola francesa do polítco in: Por uma história conceitual do político. São Paulo: Alameda, 2010.

ROSANVALLON, P. Por uma história conceitual do político. São Paulo: Alameda, 2010.

Paris : Gallimard, 1992.

Le sacre du citoyen. Histoire du suffrage universal en France.

SKINNER, Q. Visões da política sobre os métodos históricos. Algés - Portugal :

Difel, 2002. 